\title{
A interdisciplinaridade na Ciência da Informação pela perspectiva da análise de citações
}

\author{
Marcos Moraes \\ Mestre; Universidade Estadual de Londrina; marcomoraes@ msn.com \\ Ana Esmeralda Carelli \\ Doutora; Universidade Estadual de Londrina; carelliana@uol.com.br
}

\begin{abstract}
Resumo: Esta comunicação busca realizar um estudo das relações interdisciplinares que a Ciência da Informação (CI) mantém com outras áreas do conhecimento a partir da análise de citações de artigos publicados em três importantes periódicos nacionais da CI, Informação \& Sociedade: Estudos, Transinformação e Perspectivas em Ciência da Informação A CI nasce num momento histórico onde o fazer ciência sofria modificações decisivas no que tange a integração de campos dos saberes científicos, em busca de soluções para problemas sociais até então inexistentes. Trata-se da interdisciplinaridade, um movimento integrador dos saberes. Assim, a CI surge com uma forte inclinação interdisciplinar, sendo que esse aspecto da área é alvo de diversos estudos, em âmbito nacional e internacional. Foram analisadas as listas de referências de todos os artigos publicados pelas revistas nos anos de 2011 e 2012. Cada referência foi classificada, de acordo com sua temática, segundo a tabela de áreas do conhecimento do $\mathrm{CNPq}$. $\mathrm{O}$ resultado demonstrou que a $\mathrm{CI}$ recorre a aportes teóricos de muitas outras áreas do conhecimento, notadamente a Administração, Ciência da Computação, Educação e Sociologia, além da própria $\mathrm{CI}$, que representou quase metade do total de referências analisadas. Além destas, muitas outras áreas foram utilizadas como respaldo teórico dos trabalhos publicados. Ainda que os resultados observados nesta pesquisa não possam ser conclusivos, a análise de citação se mostrou uma abordagem adequada para o estudo da interdisciplinaridade na área na medida em que aponta diversas áreas que colaboram com as pesquisas em CI.
\end{abstract}

Palavras-chave: Ciência da Informação. Interdisciplinaridade. Bibliometria. Estudos Métricos. Análise de Citação.

\section{Introdução}

A Ciência da Informação (CI) desponta num momento histórico em que fazer ciência sofria modificações decisivas no que tange a integração de campos dos 
saberes científicos em busca de soluções para problemas sociais até então inexistentes. Trata-se da interdisciplinaridade, um movimento integrador dos saberes. É justamente nesse contexto que a CI surge, principalmente para dar conta de problemas como os relacionados ao crescente volume de informação, ao aparecimento de novas aplicações tecnológicas e também ao novo patamar de importância que a informação, o conhecimento e o saber adquirem.

A CI nasce com uma forte inclinação interdisciplinar, não apenas por surgir no contexto das ciências pós-modernas, mas principalmente por utilizar de aportes teóricos de outras áreas do conhecimento diante da multiplicidade temática dos problemas estudados pela CI. Tal aspecto interdisciplinar da área é alvo de diversos estudos, em âmbito nacional e internacional. Entretanto, pesquisas que discutam as relações interdisciplinares da Ciência da Informação com outras áreas do conhecimento carecem de mais densidade a fim de enriquecer e esclarecer esse importante aspecto da área. É nessa esteira que esta pesquisa se insere, do estudo das relações interdisciplinares que a Ciência da Informação mantém com outras áreas do conhecimento a partir de três diferentes abordagens métricas, sobretudo a análise de citações de três importantes periódicos nacionais da CI.

Alguns estudos já foram realizados com o intuito de refletir a natureza interdisciplinar da CI. Small (1981) por meio de um estudo de co-citação verificou as relações da CI com as Ciências Sociais no final da década de 1970. Cerca de dez anos depois um prestigiado trabalho de Linda Smith (1992) buscou refletir a respeito de possíveis abordagens para compreender as relações interdisciplinares da CI, apontando a análise de citações entre essas possíveis abordagens. E os estudos a respeito dessas citações são um dos métodos mais utilizados em estudos bibliométricos. (JAN, 2009).

No Brasil, Bicalho (2009) e Higino (2011) estudaram em suas teses as relações interdisciplinares da CI. Esses trabalhos buscaram na literatura da área compreender como ocorrem essas relações. No entanto, Smith (1992) aponta que pode existir um descompasso entre a literatura e o que realmente é praticado: "[...] existe uma aparente discrepância entre o que é dito e o que é feito." (SMITH, 1992, p, 264). 
Desse modo, percebe-se uma carência no que diz respeito a investigações do caráter interdisciplinar da CI refletido na prática da pesquisa. Sendo assim, e visto que o uso de citações revela a práxis do pesquisador, este trabalho buscou estudar as relações interdisciplinares da área sob o viés da análise de citação. Para esta verificação, parte-se do princípio que as citações referenciadas pelo autor de um texto revelam as fontes que lhe serviram de base, ou seja, são essas as teorias que respaldam o seu pensamento. Assim, em pesquisas de caráter monodisciplinar, as fontes referenciadas fazem parte, em sua maioria, do corpo de literatura da própria disciplina, publicadas em veículos considerados também da própria área. Considera-se que citações a trabalhos, autores e veículos de outras áreas indicam uma "transgressão" dos limites do campo, o que segundo a literatura, caracterizaria traços de interdisciplinaridade (MUELLER, 2007).

O principal objetivo, ao classificar as referências de artigos publicados pelas principais revistas científicas nacionais da área da Ciência da Informação, foi o de conhecer o quanto a CI cita a própria área e as outras áreas, além de identificar quais são essas outras áreas citadas e, desse modo, adensar as discussões sobre as relações interdisciplinares da CI.

\section{Interdisciplinaridade e Ciência da Informação}

Para compreender o conceito de interdisciplinaridade em Ciência da Informação é indispensável refletir acerca do pensamento científico em diferentes períodos da ciência. Mais precisamente deve-se entender os aspectos que determinaram a mudança da ciência moderna (clássica) para a ciência contemporânea (pósmoderna), ambiente em que surgiram as novas ciências, entre elas a CI.

A ciência pós-moderna traz consigo uma importante característica que marca o rompimento com o pensamento científico moderno. Trata-se da crescente reflexão sobre a interdisciplinaridade, um movimento integrador e restituidor de um saber que até então era construído pelas ciências clássicas na direção da especialização e da fragmentação isolada das disciplinas e dos campos científicos. (HISSA, 2002). 
A CI surgiu e se desenvolveu no interior desse novo contexto, a exemplo de outras tantas disciplinas sociais.

\begin{abstract}
A Ciência da Informação, que nasceu no seio de uma sociedade multifacetada e complexa, é um campo constituído por múltiplas inserções que fazem interfaces com outros campos e áreas do conhecimento; esses, por sua vez, são também perpassados por multiplicidade de fenômenos. É uma realidade complexa a exigir da Ciência da Informação um constante diálogo com essas outras áreas, o que coloca em evidência sua necessária aptidão para refletir, acatar ou refutar, e mesmo gestar aportes avindos das áreas. (SILVA, 2008, p. 8).
\end{abstract}

Saracevic (1992) aponta três importantes características das ciências pósmodernas que, segundo o autor, são encontradas na Ciência da Informação: a) natureza interdisciplinar; b) ligação com as tecnologias da informação, e c) forte dimensão social e humana. A respeito da primeira característica apontada, Saracevic afirma que a interdisciplinaridade na Ciência da Informação está em constante desenvolvimento.

A CI trabalha constantemente com o conhecimento codificado, registrado, introduzindo o objeto focado numa certa linguagem para selecionálo. Seu campo é temático, portanto lida com problemas, e, onde existem problemas, nasce sempre uma ciência de forma organizada para resolvê-los. A Ciência da Informação nasce em um contexto pós-moderno, com um compromisso de enfrentar o problema da explosão da informação que se instala e se desenvolve no início do século XX até a contemporaneidade. (LENZI; BRAMBILLA, 2006, p. 9).

O que caracteriza a Ciência da Informação desde sua gênese são as possibilidades de estudar soluções para os problemas relativos à natureza, economia, gestão, produção, processamento, organização, disseminação, recuperação, recepção e uso da informação, sejam no âmbito das organizações ou para indivíduos; informação essa registrada em suportes físicos ou, atualmente, no espaço virtual. Assim, tendo ciência de seus limites, para dar conta de todos esses problemas, os estudos da área buscam parcerias de outras disciplinas, notadamente: Lógica, Filosofia, Estatística, Biblioteconomia, Psicologia, Linguística, Informática, Matemática, Administração, Comunicação, 
Sociologia, Engenharia, Biologia, Arquivologia, Museologia, Física, Química e Semiótica (PINTO, 2007). Tais apontamentos, que evidenciam as relações que a CI historicamente mantém com outras áreas do conhecimento, realçam uma forte característica interdisciplinar, que parece já estar incorporada aos pressupostos teóricos da área.

Há ainda outros autores que indicam o caráter interdisciplinar como algo notório não apenas na Ciência da Informação, como nas demais áreas, considerando que no contexto contemporâneo não há como falar de uma prática disciplinar isolada. González de Gómez (2003), por exemplo, entende que a interdisciplinaridade gera conhecimentos a partir de diferentes modalidades de integração de conceitos, métodos ou abordagens em torno de um problema. Dessa forma, a interdisciplinaridade se desenvolveria dentro de um campo científico a fim de superar e até reformular as fronteiras disciplinares. Diferente da mera aproximação multidisciplinar, a interdisciplinaridade promoveria um diálogo entre áreas, propiciando a comunicação de conhecimentos, modelos e teorias, resultando numa ação colaborativa. (GONZÁLEZ DE GÓMEZ, 2003).

Uma ação colaborativa reclama uma coordenação entre pesquisadores e profissionais de áreas diversas, de modo a comungar seus conhecimentos, unindo-os por elos fortes através dos quais se possa distinguir uma parceria sólida e consistente entre os atores. A ocorrência de uma parceria como essa tem o potencial de agregar importantes saberes, cujo valor somente pode ser encontrado, em geral, em uma disciplina e não na outra, o que leva à necessidade de confrontá-los tendo em vista a superação de um reducionismo.

Entretanto, Smith (1992, p. 72) aponta certos aspectos que ainda carecem de mais discussão no que diz respeito à interdisciplinaridade na Ciência da Informação. Dentre essas fragilidades destacam-se:

a) Contribuição para outros campos muito fraca;

b) Necessidade de avaliar os programas educacionais para avaliar o quanto são verdadeiramente interdisciplinares, e 
c) Se a CI for prosperar como campo interdisciplinar, então mais atenção precisa ser dispensada às características da interdisciplinaridade individual.

Acerca desses três pontos por Smith, chama a atenção o fato de que há a incorporação permanente em grande parte das pesquisas em Ciência da Informação, de teorias e metodologias importadas de outras disciplinas, porém a correspondência quase sempre não é percebida, ou seja, não se observa, na mesma medida, ou até em menor grau, as contribuições que a Ciência da Informação tem trazido para as demais disciplinas. A ausência de reciprocidade na aplicação das contribuições das disciplinas em conexão, prevista nessa situação, tem como consequência a ruptura no que se espera quando há referência à interdisciplinaridade como uma reunião de disciplinas capaz de enriquecer mutuamente as partes. (SANTANA, 2012, p. 11).

Pinheiro (1999, p. 175-176), analisando o campo interdisciplinar da Ciência da Informação, conclui que os estudos e pesquisas que tratam sobre a interdisciplinaridade acabam por reconhecer que "[...] a Ciência da Informação incorpora muito mais contribuições de outras áreas, do que transfere para essas um corpo de conhecimentos gerado dentro de si mesma". Dentre os possíveis tipos de estudos possíveis que podem revelar aspectos da Ciência da Informação frente a interdisciplinaridade e sua relação com outras áreas do conhecimento está a análise de citação, um importante método dos estudos métricos.

\section{Análise de citação}

A Associação Brasileira de Normas Técnicas (2003, p. 2) define citação como a "menção de uma informação extraída de outra fonte". Assim, a partir da citação, um documento remete a outro, estabelecendo inter-relação entre eles.

As citações em trabalhos acadêmicos são utilizadas para estabelecer ligações com outros trabalhos já produzidos. E os estudos a respeito dessas citações são um dos métodos mais utilizados para estudos bibliométricos. (JAN, 2009). 
$\mathrm{Na}$ medida em que a ciência possui como um dos seus principais produtos os textos científicos publicados em revistas periódicas, as citações contidas nesses textos assumem importância essencial. Cada citação, nesse contexto, representa uma ligação, um elo entre dois atores de uma rede científica. Esse elo pode representar algumas características importantes de determinados grupos de cientistas visto que a citação, no âmbito acadêmico, apresenta dois principais aspectos: o cognitivo ou epistemológico, que indica os pressupostos teóricos utilizados pelo autor, e também o social, que por sua vez revela práticas pessoais ou de determinados grupos. "É esse aspecto que enseja possibilidades de uso das citações no estudo da ciência de maneira mais ampla, pois o nível micro (a citação) conecta-se com o macro (o sistema científico da qual a citação faz parte).” (ROMANCINI, 2010, p. 20).

Um impulso considerável na área da bibliometria foi dado pela análise de citação, cuja hipótese básica afirma que qualquer ato de citar o autor de artigo anterior é sempre significativo. (BUFREM; PRATES, 2005).

A análise de citações baseia-se na premissa de que os pesquisadores concebem seus trabalhos a partir de obras anteriores e demonstram isso citando as obras precedentes em seus textos e em uma lista ordenada e padronizada de referências. O comportamento dos cientistas fica evidente a partir do estudo dessas citações (MOREL; MOREL, 1977).

Desse modo, e diante da importância que as referências bibliográficas representam num trabalho científico, a análise dessas referências, que são denominadas no campo da bibliometria como análise de citação, vem sendo empregada como um importante instrumento metodológico de mapeamento da produção intelectual de diversas áreas do conhecimento. O emprego da análise de citação serve para diversas finalidades, como a indicação de tendências de temáticas de pesquisa, indicadores de citação e mapeamento de áreas do conhecimento mais citadas em determinada produção científica.

A técnica é utilizada, também, para a identificação de fontes de informação selecionadas por cientistas e pesquisadores para fundamentar seus estudos, a partir do levantamento de variáveis quantitativas. Os documentos citados por um autor são valiosas fontes de dados para a análise de uso e para 
mensurar demandas de informação. Estudar as fontes de informação escolhidas por uma comunidade científica permite o mapeamento de características da dinâmica de seus processos de comunicação científica.

Vanti (2002) aponta que a expansão da tecnologia que ocorreu nas últimas décadas deu novos contornos aos estudos de citação. Devido ao crescente número de conhecimento científico publicado em novos canais de comunicação científica (novas revistas científicas, repositórios digitais, sites, blogs entre outros), a necessidade de avaliar tais avanços se torna mais evidente. Desse modo, vemos um número cada vez maior de estudos que se valem da análise de citações para mapear, de diversas formas, a produção científica.

Recentemente, alguns trabalhos (TSAY, 2011, CHANG; HUANG, 2011, PERITZ; BAR-ILAN, 2002) empregaram o uso da técnica de análise de citação para investigar aspectos relacionados à interdisciplinaridade como prática de pesquisa. Assim, a metodologia desta pesquisa baseou-se nos trabalhos supracitados quanto à análise de citação.

\section{Percurso metodológico}

Os periódicos que fizeram parte da amostra da pesquisa foram selecionados levando em consideração a avaliação Qualis aferida pela CAPES, publicada no ano de 2012. Assim, foram escolhidas três únicas publicações avaliadas nos estratos A (A1 e A2) dentro de sua área. Essas revistas foram analisadas considerando os dois últimos anos de publicação, 2011 e 2012, nesse sentido foram observadas três publicações avaliadas como A1, nenhuma publicação foi avaliada como A2. O Quadro 2 elenca os periódicos selecionados: 
Quadro 2 - Periódicos selecionados (2011 - 2012)

\begin{tabular}{|c|c|c|c|}
\hline Revista & $\begin{array}{c}\text { Número de Fascículos } \\
(\mathbf{2 0 1 1 - 2 0 1 2 )}\end{array}$ & Qualis & ISSN \\
\hline Informação \& Sociedade: Estudos & 7 & $\mathrm{~A} 1$ & $1809-4783$ \\
\hline Perspectivas em Ciência da Informação & 8 & $\mathrm{~A} 1$ & $1981-5344$ \\
\hline TransInformação & 6 & $\mathrm{~A} 1$ & $0103-3786$ \\
\hline
\end{tabular}

Fonte: Dados da pesquisa.

As citações que são arroladas dentro de um artigo científico devem necessariamente ter suas fontes listadas geralmente no fim do artigo de forma padronizada. Tratam-se das referências bibliográficas; são as referências as principais fontes de informação na técnica de análise de citação, uma vez que as referências naturalmente indicam a fonte citada.

Dessa forma, a coleta dos dados se deu mediante consulta apenas aos artigos científicos encontrados nos 21 fascículos publicados pelas três revistas entre os anos de 2011 e 2012. Cada artigo teve sua lista de referências analisada uma a uma verificando a qual área do conhecimento pertencia cada referência. Para fins dessa categorização foi utilizada a "Tabela de Áreas do Conhecimento do CNPq".

A classificação das Áreas do Conhecimento tem finalidade eminentemente prática, objetivando proporcionar aos órgãos que atuam em ciência e tecnologia uma maneira ágil e funcional de agregar suas informações. A classificação permite, primordialmente, sistematizar informações sobre o desenvolvimento científico e tecnológico [...] (CONSELHO NACIONAL..., 2012).

Para aferir a classificação temática das referências foi levada em consideração a sua classificação temática pelas seguintes fontes: Catálogo Coletivo Nacional (INSTITUTO BRASILEIRO DE INFORMAÇÃO EM CIÊNCIA E TECNOLOGIA, 2013), Dedalus, Banco de Dados Bibliográficos da USP (UNIVERSIDADE DE SÃO PAULO, 2013) e World Cat (ONLINE COMPUTER LIBRARY CENTER, 2013), além do conhecimento do próprio autor da pesquisa. O CCN (Catálogo Coletivo Nacional de Publicações Seriadas) “[...] é um catálogo de acesso público que reúne informações sobre as 
coleções de publicações seriadas nacionais e estrangeiras disponíveis nas bibliotecas brasileiras". (INSTITUTO BRASILEIRO DE INFORMAÇÃO..., 2013, doc. não paginado). Dentre essas informações que o CCN disponibiliza está a classificação temática das revistas científicas, essa informação foi essencial para a classificação de referências de artigos de periódicos, que foram amplamente encontrados nesta pesquisa. O Dedalus da USP é uma base de dados que reúne as informações bibliográficas de todos os itens de todo o acervo do sistema de bibliotecas da USP. O World Cat (Catálogo Mundial), é considerado o maior catálogo bibliográfico disponível na internet. Disponibiliza registro de mais de 71.000 bibliotecas de todo o mundo. Disponibiliza dados catalográficos de mais de 150 milhões de documentos diversos (livros, revistas científicas, entre outros) e é mantido pela Online Computer Library Center (OCLC). (ONLINE COMPUTER LIBRARY CENTER, 2013, não paginado).

Também é importante informar que, além do CCN, Dedalus e World Cat, em diversos casos, não sendo possível recorrer a nenhuma dessas ferramentas, o próprio autor da pesquisa realizou a classificação temática da referência, analisando dados como título da fonte, autoria, análise do resumo ou palavras-chave e outras informações.

\section{Resultados}

O total de referências das três revistas analisadas, publicadas nos anos de $2011 \mathrm{e}$ 2012 foi de 4.647 referências. Todas as referências foram analisadas, no entanto, algumas delas apresentaram inconsistências no sentido de normalização, falta, e imprecisão de informações ou ainda não foram encontradas classificadas no CCN, Dedalus ou World Cat. Esses problemas inviabilizaram a classificação de 331 referências com o rigor e precisão. Desse modo essas 331 referências foram classificadas como "Não Identificada".

Excluindo as 331 ocorrências citadas, o total de referências classificadas foi de 4.316. O maior número de referências classificadas foi encontrado na Perspectivas em Ciências da Informação, 1801 referências classificadas, seguida 
da Informação \& Sociedade: Estudos, com 1691 referências classificadas e, por fim, a Transinformação, que teve 824 referências classificadas.

Não foi observado um padrão em relação ao número de referências por artigo, existindo casos em que os artigos apresentavam um número muito reduzido de referências e, ao contrário, casos em que artigos apresentaram uma longa lista de referências. Esses dados naturalmente não influenciaram na classificação temática das referências.

Antes de analisar a distribuição da classificação temática das referências, é muito importante saber o quanto cada fonte de informação foi utilizada. Nesse sentido, o Catálogo Coletivo Nacional, o CCN, foi o mais utilizado para aferir a classificação temática das referências. Isso pode ser explicado pelo alto número de referências de artigos de periódicos que é utilizado pela CI em suas pesquisas, fato já conhecido pela própria área e também confirmado nesta pesquisa (uma vez que esses e outros aspectos também foram observados). $\mathrm{O}$ Dedalus, catálogo do acervo da USP disponível na internet, foi a segunda fonte mais consultada no momento da classificação das referências. O autor desta pesquisa foi o terceiro maior responsável pela classificação das referências (992), e por fim, o World Cat contribuiu 656 vezes nessa tarefa.

As 4316 citações foram classificadas de acordo com suas respectivas áreas do conhecimento, levando em consideração a classificação nas fontes consultadas já mencionadas anteriormente. A Tabela 2, mostrada a seguir, elenca a distribuição do total de referências analisadas, agrupadas de acordo com as áreas do conhecimento nas quais foram classificadas, observando sempre os critérios metodológicos adotados nesta pesquisa. Assim resultou-se o rol de todas as áreas do conhecimento que foram citadas nos anos de 2011 e 2012 pelos artigos científicos dos periódicos estudados. 
Tabela 2 - Classificação Temática Geral das Referências Classificadas

\section{Contagem Total de Classificação Temática}

\begin{tabular}{l|c|c|l|c|c}
\hline Área & $\mathrm{T}$ & \multicolumn{1}{|c|}{$\%$} & Área & $\mathrm{T}$ & $\%$ \\
\hline Ciência da Informação & 2045 & $47,38 \%$ & Antropologia & 24 & $0,56 \%$ \\
\hline Administração & 613 & $14,20 \%$ & Ciência Política & 22 & $0,51 \%$ \\
Ciência da Computação & 226 & $5,24 \%$ & $\begin{array}{l}\text { Probabilidade } \\
\text { Estatística }\end{array}$ & & \\
& & & $\begin{array}{l}\text { Engenharia } \\
\text { Produção }\end{array}$ & & $0,30 \%$ \\
Educação & 222 & $5,14 \%$ & 13 & $0,30 \%$ \\
Sociologia & 197 & $4,56 \%$ & Biologia & 11 & $0,25 \%$ \\
Ciências & 141 & $3,27 \%$ & Saúde coletiva & 8 & $0,19 \%$ \\
Filosofia & 129 & $2,99 \%$ & Arqueologia & 8 & $0,19 \%$ \\
Comunicação & 109 & $2,53 \%$ & Física & 7 & $0,16 \%$ \\
Psicologia & 77 & $1,78 \%$ & Serviço Social & 6 & $0,14 \%$ \\
\hline Letras & 76 & $1,76 \%$ & Matemática & 6 & $0,14 \%$ \\
História & 72 & $1,67 \%$ & Teologia & 5 & $0,12 \%$ \\
Ciências Sociais & 61 & $1,41 \%$ & Ecologia & 5 & $0,12 \%$ \\
Direito & 60 & $1,39 \%$ & Geografia & 5 & $0,12 \%$ \\
\hline Economia & 38 & $0,88 \%$ & Engenharia Têxtil & 3 & $0,07 \%$ \\
\hline Artes & 37 & $0,86 \%$ & Engenharia Elétrica & 2 & $0,05 \%$ \\
\hline Medicina & 34 & $0,79 \%$ & Química & 2 & $0,05 \%$ \\
Museologia & 27 & $0,63 \%$ & Outras áreas & 12 & $0,24 \%$ \\
\hline
\end{tabular}

Fonte: Dados da pesquisa

Como já foi mencionado anteriormente neste trabalho, houve casos em que não foi possível identificar com precisão e rigor a qual área do conhecimento a referência analisada pertencia. Nesses casos foram classificadas como "Não Identificada", somando um número de 331 referências. Muito embora esse número represente aproximadamente $7 \%$ do total de referências analisadas, tal fato não prejudicou o resultado final da pesquisa, tampouco representou um obstáculo para atingir o objetivo esperado nessa fase do trabalho.

Foram identificadas citações a 45 diferentes áreas do conhecimento, num número que variou de 2.045 referências para a área mais citada, no caso a própria Ciência da Informação, a apenas uma citação para as áreas que foram menos citadas pelo conjunto de artigos analisados. Nesse caso falamos de doze diferentes áreas do conhecimento, nominadas na Tabela 2 de "Outras áreas", a 
saber: Agronomia, Relações Internacionais, Educação Física, Biomedicina, Enfermagem, Engenharia Civil, Planejamento Urbano e Regional, Desenho Industrial, Relações Públicas, Engenharia agrícola, Odontologia e Fisioterapia.

Assim como houve um número grande de áreas citadas, o número de vezes que cada área foi citada também apresentou uma grande variação, não sendo observada uma distribuição uniforme de citações para cada uma das 45 áreas. Assim sendo, podemos observar, ao menos no que tange a citações a outras áreas, uma altíssima relação da Ciência da Informação com algumas áreas, tais como a Administração, em especial; uma relação alta com a Ciência da Computação e a Educação, por exemplo; uma relação média com áreas como a Psicologia, Comunicação, Letras e História; uma relação considerada baixa com áreas como a Engenharia de Produção e a Probabilidade e Estatística, além de uma relação considerada baixíssima com as áreas que foram menos citadas, como a Agronomia, Relações Internacionais e outras que receberam apenas uma citação e já foram mencionadas no parágrafo anterior.

Ainda no que se refere ao grau de relação da CI com outras áreas do conhecimento refletido nas citações, observa-se que 53 outras áreas do conhecimento, das 98 que se encontram na tabela de áreas do conhecimento do CNPq não foram citadas nenhuma vez, ou seja, nenhuma das referências classificadas era de fontes dessas áreas. Desse modo, podemos dizer que foi observado que a CI não teve nenhuma relação com essas áreas.

Nota-se que a Administração, área normalmente indicada como de grande contribuição para a CI, foi de fato bem citada. Percentualmente a Administração representou $14,20 \%$ do total de referências analisadas, um número menor que o da própria Ciência da Informação, entretanto maior que os 5,24\% da Ciência da Computação, que foi a terceira dentre as 45 citadas. Um dado relevante a ser considerado no sentido do que foi exposto trata-se das temáticas dos artigos analisados. Sabemos que na ciência como um todo, determinados assuntos são consideravelmente mais abordados do que outros em diferentes épocas e contextos (sociais, históricos, econômicos e outros). Logo, cabe apontar que no caso desta pesquisa houve um número bastante considerável de artigos que trataram do tema de gestão do conhecimento. 
A gestão do conhecimento é um tema que vem ganhando importância recente por sua atualidade e forte interlocução com questões estratégicas e econômicas ligadas a informação e ao conhecimento. Esse campo de estudo tem uma característica interdisciplinar evidente, sendo objeto de pesquisa de diversas áreas, sobretudo a Administração e a Ciência da Informação. Sendo assim, a classificação temática de parte das referências encontradas nesses trabalhos foi um ponto decisivo para o resultado aqui discutido.

Como a metodologia desta pesquisa preconizava o uso da Tabela de Áreas do Conhecimento do CNPq como padrão de áreas do conhecimento, bem como utilizou o World Cat, a base Dedalus e o Catálogo Coletivo Nacional para observar a classificação das fontes, a escolha para as referências que tratavam da gestão do conhecimento deu-se para a Administração, área em que as referências em questão encontravam-se classificadas tanto no World Cat quanto na base Dedalus e CCN.

Assim como ocorreu com a Administração, foi percebido que as áreas citadas dependem, naturalmente, da temática dos trabalhos publicados. No Quadro 1 deste trabalho mostramos que a autora Pinto (2007) aponta, no que ela denomina de "Estrutura interdisciplinar da Ciência da Informação", as disciplinas da CI e as respectivas áreas do conhecimento que contribuem com os estudos dentro de cada disciplina. Para a autora, a Administração contribui fortemente com os estudos que tratam sobre o mercado da informação, o direito autoral, a indústria da informação e claro, a gestão da informação e do conhecimento. Desse modo os resultados da análise de citação refletem não somente áreas interdisciplinares com a CI, mas também quais temáticas estão sendo mais abordadas pelos pesquisadores da área.

Nesse sentido, podemos afirmar que no período estudado (2011/2012), as relações interdisciplinares da CI com a Administração foram mais intensas do que em relação às outras áreas do conhecimento, principalmente pelo crescente interesse da CI pela gestão do conhecimento notado neste estudo.

Já a Ciência da Computação, terceira área mais citada, é amplamente utilizada, segundo Pinto (2007), em estudos sobre Informática documentária, bases e bancos de dados, bibliotecas digitais, recuperação automática de 
informação, softwares, hipertexto e demais tecnologias da informação. Esses são temas recorrentes dentro das publicações científicas da área e ganharam força nos últimos anos com o crescente interesse da CI e de toda a comunidade científica com questões relativas aos repositórios digitais (temáticos e institucionais), acesso e software livre, entre outros temas de forte inclinação tecnológica. Assim, é correto afirmar que a contribuição da Ciência da Computação para a CI é consideravelmente grande, ainda que para autores como Pinheiro (2006), essa contribuição tenha um caráter mais instrumental.

Desse modo, podemos dizer que os resultados percentuais da análise de citação refletem quais os temas mais recorrentes nos últimos anos nas três revistas estudadas.

Ainda sobre o percentual das áreas citadas, exceto no caso da própria CI e da Administração, não foi percebida uma grande diferença pelo menos entre as dez primeiras áreas mais citadas que foram, nessa ordem: Ciência da Informação (47,38\%), Administração (14,20\%), Ciência da Computação (5,24\%), Educação (5,14\%), Sociologia (4,56\%), Ciências (3,27\%), Filosofia (2,99\%), Comunicação (2,53\%), Psicologia (1,78\%) e Letras (1,76\%).

Em comparação aos resultados de pesquisas indicadas neste trabalho, que foram realizadas em âmbito internacional por Tsay (2011) e Peritz e Bar-Ilan (2002), percebemos um resultado similar no que se refere à representação de citações da CI nas publicações estudadas.

Na pesquisa de Tsay (2011), a Ciência da Informação foi responsável por 46,9\% das citações no JASIST, 52,9\%, no Information Processing and Management, e $64,1 \%$ no Journal fo Documentation, que mostrou um percentual maior que as demais e ao que foi percebido nesta pesquisa. Ainda no trabalho de Tsay (2011), sobre as outras áreas do conhecimento mais citadas pelas revistas estrangeiras, foi detectado que Ciências (geral), foi a segunda área mais citada nos três periódicos, já no caso desta pesquisa foi a sexta área mais citada. Em relação às outras áreas da pesquisa de Tsay (2011) que foram muito citadas, verificaram-se as seguintes áreas: Ciências Sociais, Ciência da Computação, Letras, Filosofia, Psicologia e Medicina. Nota-se, portanto, uma similaridade nas áreas, exceto pela Medicina e pela Educação. A Medicina foi 
bastante citada pelas três revistas estrangeiras, porém pouco citada pelas três publicações nacionais, ao passo que no caso da Educação aconteceu o contrário: foi bastante citada pelas revistas nacionais e pouco apareceu em citações das publicações estrangeiras.

Na pesquisa de Peritz e Bar-Ilan (2002), ao analisarem as referências da revista Scientometrics, especializada em estudos métricos, averiguaram que fontes da Ciência da Informação foram amplamente citadas, seguidas da Filosofia, Sociologia, Ciências no geral. No estudo da revista Scientometrics, a Medicina também figura como uma das áreas mais citadas, algo não percebido nas revistas nacionais.

A respeito da proporção notada entre citações da CI e das outras áreas citadas, percebemos que a Ciência da Informação representa a área mais citada pelos artigos publicados nas três revistas durante o período estudado. A proporção das citações da própria área foi maior quando comparada á segunda mais citada, a Administração (47,38\% de referências da CI e 14,20\% da Administração). Desse modo, fica evidente que numericamente, a Ciência da Informação recorre mais ao seu próprio arcabouço teórico do que qualquer outra área do conhecimento para a produção de pesquisas em CI.

Entretanto, quando visualizamos o peso das referências da CI em relação à soma de todas as outras áreas citadas podemos perceber que as outras áreas, juntas, são mais citadas pela CI em suas pesquisas. Nesse caso, a proporção de citações da própria área é de 47,38\% em relação a soma de todas as outras áreas juntas, que foi de 52,68\%, como é mostrado no Gráfico 1. 


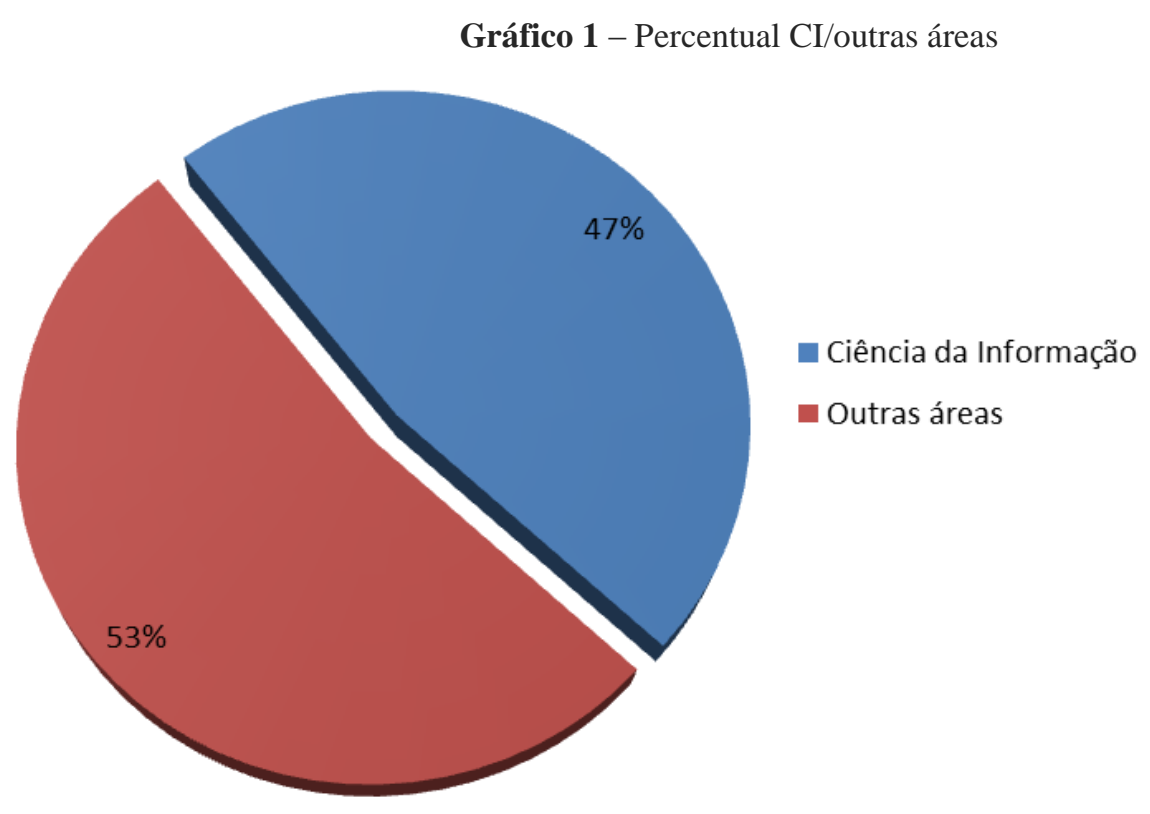

Fonte: Dados da pesquisa

Quando se observa que a Ciência da informação é a área mais citada do que qualquer outra em suas próprias produções científicas, podemos constatar que o conhecimento da área, ao menos na realidade observada nesta pesquisa, fornece boa parte dos subsídios teóricos necessários para o desenvolvimento de suas pesquisas. Entretanto, o resultado também aponta que as referências de todas as outras áreas somadas é proporcionalmente maior do que o número de referências da CI, isso evidencia que a área vem recorrendo a diversas outras áreas do conhecimento para a produção de suas pesquisas.

Cabe ressaltar que a característica apresentada pela CI no que se refere a citação a diversas outras áreas do conhecimento em sua produção científica, nos remete justamente a um dos mais conhecidos traços das ciências pós-modernas: a intensa troca de conhecimentos, métodos, conceitos e demais aspectos entre as áreas do conhecimento. Quando essa interação ocorre, naturalmente ela se encontra refletida nas citações, como foi observado nesta pesquisa.

$\mathrm{Na}$ classificação temática do total de referências classificadas, ficou evidente o traço de interdisciplinaridade da Ciência da Informação refletido nas 
citações a diversas áreas do conhecimento. Sabemos, entretanto, que cada revista científica tem suas próprias características, linha editorial e outras especificidades, sendo assim, o perfil das revistas e dos trabalhos que publicam notadamente pode ser diferente de outros periódicos científicos.

\section{Considerações finais}

Os questionamentos que surgiram com a realização desta pesquisa nos levam a refletir sobre a natureza das ciências interdisciplinares, que têm, como o próprio nome sugere, fortes relações com outras áreas do conhecimento.

No caso específico da Ciência da Informação, sabemos que a área se dedica a estudar soluções para os problemas relativos à natureza, economia, gestão, produção, processamento, organização, disseminação, recuperação, recepção e uso da informação, sejam no âmbito das organizações ou para indivíduos; informação essa registrada em suportes físicos ou, atualmente, no espaço virtual. Nota-se, portanto, as múltiplas inserções da CI, o que naturalmente leva a área a ter relações interdisciplinares com outras áreas.

Nesta pesquisa, foi observado um grande número de citações da Administração, o que pode ser explicado, em grande parte, pelo crescente interesse pelos estudos em gestão do conhecimento, como já explicado. Desse modo, novos estudos podem comprovar a tese de que as relações interdisciplinares na Ciência da Informação dependem grandemente dos temas estudados a cada momento, ou ainda refutar essa ideia.

Além das temáticas em evidência, a linha editorial, o foco, o escopo e a equipe editorial das revistas, também têm certa influência em resultados de estudo como este. Esses aspectos norteiam a seleção dos trabalhos que são publicados nas revistas e consequentemente têm certo impacto em indicadores métricos como os que foram estudados nesta pesquisa.

Percebemos ainda um número grande de áreas do conhecimento citadas. Foram encontradas citações a 45 diferentes áreas, ainda que algumas delas apresentassem um número bastante baixo de citações. Esse dado corrobora com 
afirmações de que parece haver uma dependência, por parte da CI, de teorias de outras ciências (GARCIA, 2002; SIHIRIAL; LOURENÇO, 2002). No entanto, essa dependência se justifica tanto por ser a CI uma área relativamente jovem, quanto pelo fato de a área ser, de fato, uma ciência interdisciplinar e, por esse motivo, receber contribuições de outras disciplinas para a construção de seu arcabouço teórico. Tais percepções vão ao encontro do que disse Saracevic (1992), quando afirmou que a interdisciplinaridade da área encontra-se em constante modificação. Segundo o autor, portanto, as relações que a CI tem com outras áreas do conhecimento vão se modificando ao longo do tempo.

Nesse ponto, cabe então relativizar a questão da dependência da CI de outras áreas, buscando refletir se, pelo seu ainda curto percurso na longa história das ciências, pela natureza de seus problemas e principalmente pelas características interdisciplinares inerentes às ciências pós-modernas, a “dependência de outras áreas" seria, na verdade, uma característica própria da área.

Ainda sobre a "dependência" aqui citada, não se pode afirmar que esta dependência diminuiu ou aumentou, visto que não foram encontrados estudos como este em âmbito nacional que servissem de parâmetro comparativo. Desse modo, a principal contribuição deste estudo foi de fornecer um "retrato", ou seja, um panorama do momento atual da Ciência da Informação no que se refere a suas interações com outras áreas do conhecimento refletidas nos índices métricos utilizados.

Estudos posteriores poderão fornecer novos "retratos", sendo possível observar se o nível de interação que a Ciência da Informação tem com outras áreas diminui, cresce ou permanece. Além disso, será possível identificar se as áreas e as medidas de interação continuam as mesmas ou se modificam. Essas discussões são fundamentais para adensar as discussões a respeito do campo da epistemologia da área. 


\section{Referências}

BICALHO, L.; OLIVEIRA, M. A teoria e a prática da interdisciplinaridade em Ciência da Informação. Perspectivas em Ciência da Informação, v.16, n.13 p.47-74, jul./set. 2011. Disponível em:

<http://portaldeperiodicos.eci.ufmg.br/index.php/pci/article/view/1245>. Acesso em: 12 jan. 2014.

BUFREM, L.; PRATES, Y. O saber científico registrado e as práticas de mensuração da informação. Ciência da Informação, Brasília, v. 34, n. 2, p. 925, maio/ago. 2005. Disponível em: < http://www.scielo.br/pdf/ci/v34n2/28551> Acesso em 10 maio 2012.

CHANG, Y. W.; HUANG, M. H. A Study of the evolution of interdisciplinarity in library and information science: using three bibliometric. Journal of the American Society for Information Science and Technology, v. 23, 2011, p. 22-33. Disponivel em:

<http://onlinelibrary.wiley.com/doi/10.1002/asi.21649/abstract>. Acesso em 07 abr. 2013.

\section{CONSELHO NACIONAL DE DESENVOLVIMENTO CIENTÍFICO E} TECNOLÓGICO. Tabela de áreas do conhecimento. 2012. Disponível em: $<$ www.cnpq.br/documents/10157/TabeladeAreasdoConhecimento.pdf $>$. Acesso em: 23 maio. 2013.

GARCIA, J. C. R. Conferências do Geórgia Institute of Technology e a ciência da informação: "de volta para o futuro". Informação \& Sociedade: Estudos, João Pessoa, v. 12, n. 1, p. 54-66, 2002. Disponível em:

<http://www.ies.ufpb.br/ojs/index.php/ies/article/view/153>. Acesso em: 14 jul. 2014.

GONZÁLEZ DE GÓMEZ, M. N. Escopo e abrangência da ciência da informação e a pós-graduação na área: anotações para uma reflexão.

Transinformação, v.15, n.1, p.31-43, jan./abr. 2003.

HIGINO, A. F. B. Ciência da informação, interdisciplinaridade e transdisciplinaridade [manuscrito]: um estudo do contexto brasileiro com foco no ENANCIB. 2011. 362 fl. Tese (Doutorado) - Universidade Federal de Minas Gerais, Escola de Ciência da Informação. UFMG: Belo Horizonte, 2011. HISSA, C. E. V. A mobilidade das fronteiras: inserções da geografia na crise da modernidade. Belo Horizonte: Ed. UFMG, 2002.

INSTITUTO BRASILEIRO DE INFORMAÇÃO EM CIÊNCIA E TECNOLOGIA. Catálogo Coletivo Nacional de Publicações Seriadas (CCN). 2013. Disponível em: <http://www.ibict.br/informacao-para-ciencia-tecnologia- 
e-inovacao\%20/catalogo-coletivo-nacional-de-publicacoesseriadas\%28ccn\%29>. Acesso em: 10 ago. 2014.

JAN, R. Citation analysis of Library Trends. Webology, Iran, v. 6, n. 1, Mar, 2009. Disponível em: <http://www.webology.org/2009/v6n1/a67.html >. Acesso em: 15 abr. 2013.

LENZI, L. A. F.; BRAMBILA, E. Z. Ciência da informação, ciência e revolução científica: breve histórico e reflexões. Informação \& Informação, Londrina, v. 11, n. 1, jan. / jun. 2006. Disponível em: <http://www.uel.br/revistas/uel/index.php/informacao/article/view/1679/0 > Acesso em: 24 jun. 2013.

MOREL, R. L. de M.; MOREL, C. M. Um estudo sobre a produção científica brasileira, segundo os dados do Institute for Scientific Information (ISI).

Ciência da Informação, Brasília, v. 6, n. 2, p. 99-109, 1977. Disponível em: <http://revista.ibict.br/ciinf/index.php/ciinf/article/viewFile/1677/1283>. Acesso em: 15 abr. 2013.

MUELLER, S. P. M. Será a Ciência da Informação brasileira realmente interdisciplinar? Um retrato instantâneo de suas fontes e assuntos. In: In: PINTO, V. B.; CAVALCANTE, L. E.; SILVA NETO, C. Ciência da Informação: abordagens transdisciplinares e aplicações. Fortaleza: Edições UFC, 2007. p. 143-163.

ONLINE COMPUTER LIBRARY CENTER. World Cat. 2013. Disponível em: 〈http://oclc.org/pt-americalatina/worldcat.html> Acesso em: 10 ago. 2014.

PERITZ, B. C.; BAR-ILAN, J. The sources used by bibliometricsscientometrics as reflected in references. Scientometrics, v, 54, N, 2, 2002, p. 269-284. Disponível em: < www.phil.muni.cz/ bjelinko/docs/fulltext-2.pdf>. Acesso em 15 maio. 2013.

PINHEIRO, L. V. Ciência da informação: desdobramentos disciplinares, interdisciplinaridade e transdisciplinaridade. 2006. Disponível em: <http://www.uff.br/ppgci/editais/lenavanialeituras.pdf>. Acesso em: 23 fev.2014. . Campo interdisciplinar da Ciência da Informação: fronteiras remotas e recentes. In: Ciência da Informação, Ciências Sociais e interdisciplinaridade. Brasília: IBICT, 1999. p.155-182.

PINTO, V. B. Interdisciplinaridade na Ciência da Informação: aplicabilidade sobre a representação indexal. In: PINTO, V. B.; CAVALCANTE, L. E.; SILVA NETO, C. Ciência da Informação: abordagens transdisciplinares e aplicações. Fortaleza: Edições UFC, 2007. p. 105-142.

ROMANCINI, Richard. O que é uma citação? A análise de citação na ciência. Intexto, Porto Alegre: UFRGS, v. 2, n. 23, p. 20-35, julho/dezembro 2010. 
Disponível em: <http://seer.ufrgs.br/intexto/article/view/15885> . Acesso em 10 set. 2013.

SANTANA, G. H. C. A Ciência da Informação e sua consolidação em face da interdisciplinaridade. Encontros Bibli, Florianópolis, v. 17, n. 35, p.1-26, set./dez., 2012. Disponível em:

<http://www.redalyc.org/articulo.oa?id=14724821002 >. Acesso em: 14 set. 2013.

SARACEVIC, T. Information Science: origin, evolution and relations. In: VAKKARI, Pertti, CRONIN, B. (Eds.). Conceptions of Library and Information Science; historical, empirical and theoretical perspectives. THE INTERNATIONAL CONFERENCE FOR THE CELEBRATION OF $20^{\mathrm{TH}}$ ANNIVERSARY OF THE DEPARTMENT OF INFORMATION STUDIES OF UNIVERSITY OF TAMPERE, 1991, Proceedings... Finland. London, Los Angeles: Taylor Graham, 1992. p. 5-27. Disponível em: <http://comminfo.rutgers.edu/ kantor/601/Readings2004/Week2/w2R1.PDF>. Acesso em: 13 abr. 2013

SILVA. T. E. da. (Org.). Interdisciplinaridade e transversalidade em Ciência da Informação. Recife: Néctar, 2008.

SILVEIRA, M. A. A.; BAZI, R. E. R. As referências nos estudos de citação: algumas questões para discussão. Datagramazero, Rio de Janeiro, v. 10, n. 4, ago. 2009. Disponível em: <http://www.dgz.org.br/ago09/Art_04.htm>. Acesso em: 15 abr. 2013.

SIHIRAL, A. B.; LOURENÇO, C. A. Informação e conhecimento: aspectos filosóficos e informacionais. Informação e Sociedade: Estudos, João Pessoa, v. 12, n. 1, 2002. Disponível em:

<http://www.ies.ufpb.br/ojs/index.php/ies/article/view/154>. Acesso em 16 jul. 2014.

SMALL, H. The relationship of information science to the social sciences: a cocitation analiys. Information Processing \& Management, Elmsford, v, 17, p. 39-50, 1981. Disponível em:

<http://www.sciencedirect.com/science/article/pii/0306457381900406>. Acesso em: 10 abr. 2013.

SMITH, L. Interdisciplinarity: approaches to understanding library and information science as an interdisciplinary field. In: VAKKARI, P.; CRONIN, B. (eds). Conceptions of library and information science: historical, empirical and theoretical perspectives. Londres, Los Angeles: Taylor Graham, 1992, p. 253-267. Disponível em:

<https://www.gslis.utexas.edu/ itesm/html\%20original/abstract17.pdf $>$. Acesso em: 20 jan. 2013. 
TSAY, M. A bibliometric analysis and comparison on three information science journals: JASIST, IPM, JOD, 1998---2008. Scientometrics, v. 89, n. 2, p. 591606, Nov. 2011. Disponível em: < http://link.springer.com/article/10.1007\%2Fs11192-011-0460-4>. Acesso em: 12 jan. 2013.

UNIVERSIDADE DE SÃO PAULO. Dedalus: banco de dados bibliográficos da USP. 2013. <http://dedalus.usp.br/>. Acesso em: 14 mar. 2012.

VANTI, N. A. P. Da bibliometria à webometria: uma exploração conceitual dos mecanismos utilizados para medir o registro da informação e a difusão do conhecimento. Ciência da Informação, Brasília, v. 31, n. 2, p. 152-162, maio/ago. 2002. Disponível em: < http://www.scielo.br/pdf/ci/v31n2/12918.pdf> Acesso em 12 maio 2012.

\title{
The interdisciplinarity in Information Science from the perspective of citation analysis
}

\begin{abstract}
The Information Science (IC) comes at a historic moment where doing science suffered decisive modifications regarding the integration of fields of scientific knowledge, seeking solutions to social problems that did not exist. It is interdisciplinary movement of knowledge. Therefore, the IC was born with a strong interdisciplinary inclination, and this aspect is the subject of several studies, both nationally and internationally. It is in this treadmill that this research is located, to conduct a study of interdisciplinary relations that Information Science has with other areas of knowledge from citation analysis article published in three national journals of important CI, Informação \& Sociedade: Estudos, Transinformação e Perspectivas em Ciência da Informação. The reference lists of all articles published by those periodicals in the years 2011 and 2012 were analyzed. Each reference was classified, according to their subject, in consonance with the $\mathrm{CNPq}$ areas of knowledge table. The results showed that the CI uses theoretical contributions in many other areas of
\end{abstract}


knowledge, notably Administration, Computer Science, Education and Sociology, as well as CI itself, which accounted for nearly half of all analyzed references. Apart from these, many other areas were used as theoretical support of the published works. Although the results observed in this study may not be conclusive, citation analysis proved to be an appropriate approach to the study of interdisciplinarity, which reveals that several areas have been contributing to research in IC.

Keywords: Information Science. Interdisciplinarity. Bibliometric Studies. Citation Analysis.

Recebido: 07/06/2015

Aceito: $20 / 11 / 2015$ 